\title{
Tempo Digital: Quando a escola invade o smartphone
}

\author{
Maria Luísa Luís Duarte \\ Escola Portuguesa de Moçambique - CELP
}

\section{RESUMO}

Este artigo deriva da investigação de mestrado em que se procura compreender que usos os adolescentes desta geração, conhecida como millennials (ou nativos digitais), estão a dar aos seus smartphones num dado contexto escolar português. Tendo em conta que os nossos jovens (e também os adultos) passam grande parte do seu tempo "agarrados" aos pequenos dispositivos eletrónicos, a presente investigação olha para este problema como uma oportunidade de, mediante um uso didático, produzir conteúdos artísticos. Ao mesmo tempo, ajuda os jovens alunos "produtores/consumidores" a reconhecerem-se na produção de subjetividade inerente a determinadas propostas de trabalho realizadas no âmbito da disciplina de História da Cultura e das Artes.

Partindo dos conceitos inerentes às disciplinas de Educação Artística e da seleção e estudo de uma obra de arte, e tendo como objeto de estudo a autorepresentação, o aluno (re)cria (a obra por si selecionada) através do uso do smartphone, mobilizando competências transversais (técnicas, estéticas e metodológicas) num processo que se quer criativo.

No processo criativo estão contemplados vários aspetos que podem, e devem, ser aprofundados, nomeadamente a questão do tempo. O tempo em que vivemos é um tempo inesperado! Tempo de reclusão, de distanciamento, de confinamento!

Procura-se indagar se o atual contexto de confinamento pode constituir uma oportunidade de refletir sobre o uso didático do smartphone para produzir conteúdos artísticos mantendo os princípios de igualdade e equidade.

Palavras-chave: Prossumidor, Adolescência(s), Tempo, Tecnologias, Didática 


\section{RESUMO}

This article derives from the master's research in which it seeks to understand what uses the teenagers of this generation, known as millennials (or digital natives), are giving to their smartphones in a given Portuguese school context. Bearing in mind that our young people (as well as adults) spend a large part of their time "clinging" to small electronic devices, the present investigation looks at this problem as an opportunity to produce artistic content through a didactic use. At the same time, it helps young "producer / consumer" students to recognize themselves in the production of subjectivity inherent in certain work proposals carried out within the scope of the History of Culture and Arts. Starting from the concepts inherent to the disciplines of Artistic Education and the selection and study of a work of art, and having self-representation as the object of study, the student (re) creates (the work selected by himself) through the use of the smartphone, mobilizing skills transversal (technical, aesthetic and methodological) in a process that wants to be creative. In the creative process several aspects are contemplated that can, and should, be deepened, namely the question of time. The time we live in is an unexpected time! Time of seclusion, distance, confinement! We seek to ask whether the current context of confinement can provide an opportunity to reflect on the didactic use of the smartphone to produce artistic content while maintaining the principles of equality and equity.

Palavras-chave: Prosecutor, Adolescence (s), Time, Technologies, Didactics. 


\section{INTRODUÇÃO}

Esta reflexão pareceu-nos tanto mais atual e significativa quanto maior é a consciência de que a educação artística parece estar a atravessar um conjunto de paradoxos naquilo que dantes constituía o seu ADN didático-pedagógico: a sua essencialidade plástica. Atualmente, a pandemia COVID-19 tem vindo a colocar à Humanidade, num curto espaço de tempo, grandes desafios pessoais e, sobretudo coletivos. De um momento para o outro, vimo-nos confrontados com a necessidade de reorganizar a nossa vida e reinventar rotinas. O sistema educativo não foge a esta realidade e as escolas têm de se reorganizar para continuar a levar a cabo a sua missão pedagógica e didática.

\section{Enquadramento teórico}

A literatura aponta em primeiro lugar para a necessidade de se equacionar o contributo das tecnologias não como um meio de expansão de técnicas, mas antes como um meio com potencial para ampliar o pensamento e a capacidade de expressão humana para ler, reler, criar e recriar o mundo. Nesta conformidade, e porque as tecnologias proporcionam espaço e oportunidade para a criação de trabalhos artísticos autênticos, indo além das abordagens tradicionais para olhar e pensar todos os domínios culturais, a diversidade de expressão e a reflexão crítica (Costa et al., 2012:76-77).

Arantes, M; Valadares, F. (2014:2) consideram que a apropriação e ressignificação das diferentes linguagens artísticas, em especial da imagem, por meio dos recursos tecnológicos (fotografia, vídeo, scanner, computador, câmera, entre outros) torna-se um desafio e uma possibilidade.

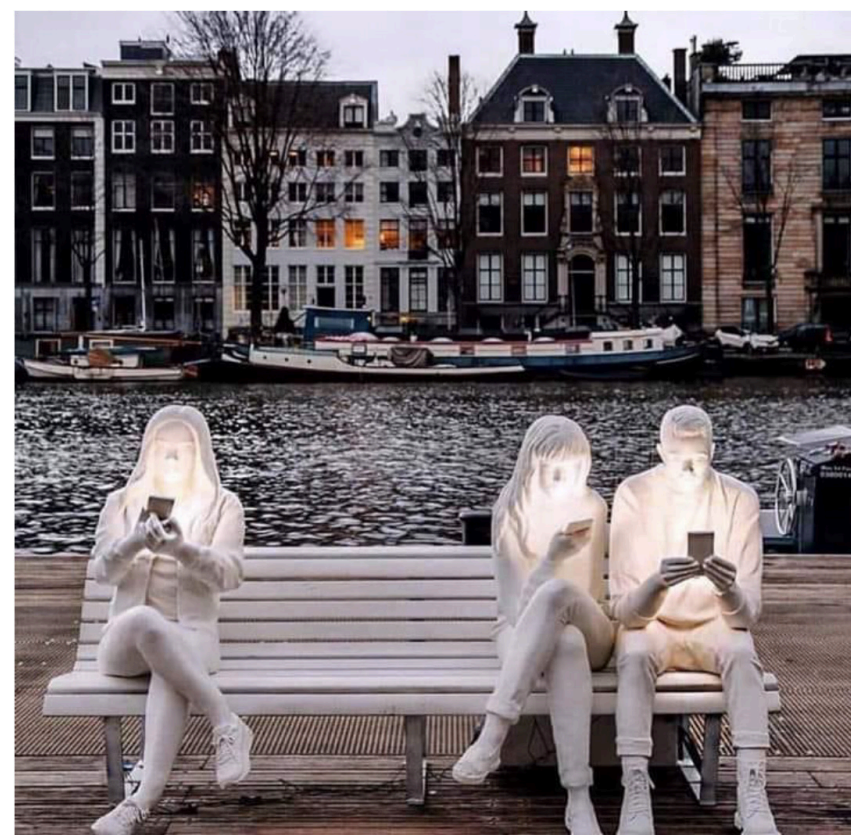

Figura 1. "Absorbed by light", 2018

Instalação escultórica, Amsterdam, Holanda Gari Lucas en Colaboração con karoline Linz
Além do uso de software específico, ferramentas de coleta e processamento de imagens, hoje os recursos disponíveis na Internet permitem inúmeras linhas de fuga (...). Existem estúdios interativos disponíveis numa variedade de galerias de arte e museus virtuais. (Costa et al., 2012:77).

A representação visual é cada vez mais influente na formação de nossas visões de mundo" Chaplin (2003:1.

Figura 1

\subsection{Enquadramento do tema | Tempo digital}

Será que o atual contexto de confinamento pode constituir uma oportunidade de refletir sobre o uso didático do smartphone para produzir conteúdos artísticos? A nossa observação etnográfica informal na sala de aula informounos que muitos de nossos alunos preferem o tablet ou smartphone quando descrevem as suas primeiras ideias para desenvolver qualquer projeto de artes visuais. A educação artística atravessa paradoxos na sua essencialidade plástica: o desenho desapareceu do papel, substituído pelo ecrã. (Queiroz, 2016).

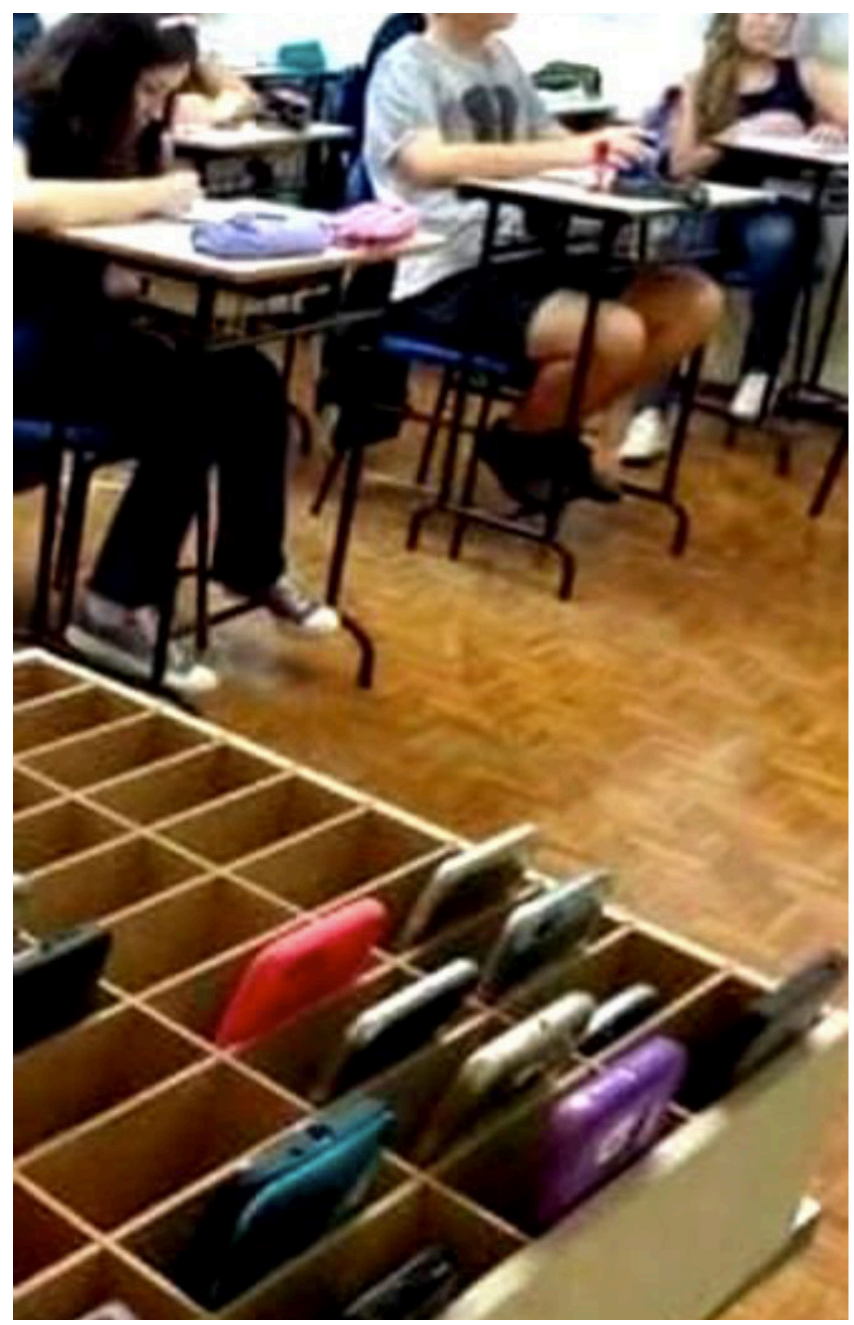

Figura 2. Pormenor da sala de aula- caixa com smartphones dos alunos. Fonte: Profa. Maria Luísa Duarte. 


\subsubsection{Smartphones : Divinização ou demonização?}

Não se pretende glorificar a utilização sistemática destes meios, mas compreender de que modo esta dependência do smartphone se pode converter numa mais valia no processo de ensino/aprendizagem da Educação Artística, atendendo à realidade- EÅD- da(s) escola(s) e ao perfil do aluno do século XXI em que a educação digital rivaliza com a educação analógica.).

\section{FIGURA 2}

Alguns autores como Nicolas Carr (2012), Amber Case (2014) e Susan Greenfield (2015) a partir das ciências da comunicação, da antropologia e da neurociência, têm chamado a atenção para as profundas alterações que a revolução digital em curso têm vindo a provocar sobre as pessoas.

Hoje recebo (recebemos) dezenas de e-mails todos os dias, todos de pessoas que esperam uma resposta imediata. Pensamos que estávamos economizando tempo; em vez disso, colocamos a roda da vida para girar a dez vezes sua velocidade anterior e tornamos nossos dias mais ansiosos e agitados. (Harari, 2011:95)

Num contexto de pandemia, a comunicação faz-se à distância através dos meios tecnológicos mais próximos e imediatos.

A tecnologia já está tão incorporada nas nossas vidas diárias que muitas vezes é difícil voltar atrás para perceber como estamos a mudar com ela. (Case, 2014, p.9).

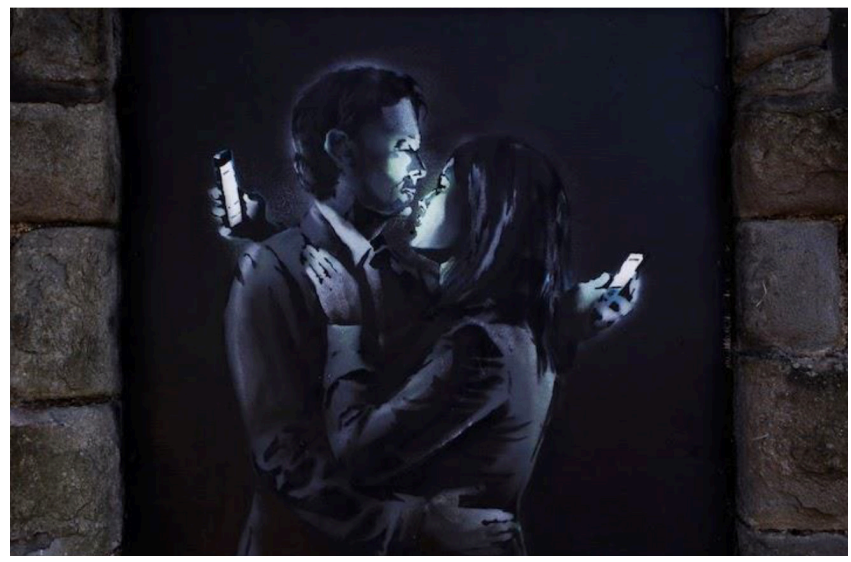

Figura 3. Banksy, stencil , 2014, Clement Street, Bristol, Reino Unido - Fonte: Profa. Maria Luísa Duarte

Passamos horas infinitas sentados frente a écrans, dedilhanho silenciosamente em que o nosso corpo e, em especial o nosso cérebro, se adapta.

Como o tempo que negligenciamos entre os elos substitui o tempo que dedicamos à reflexão e contemplação silenciosas, os circuitos que permitiam esses processos e funções intelectuais antigos enfraquecem e começam-se a decompor. $\mathrm{O}$ cérebro recicla neurônios não utilizados e sinapses e dá-Ihes outras tarefas mais urgentes. Adquirimos novas habilidades e novas perspectivas, mas perdemos outras (...). (Carr, 2012:151).

\subsubsection{Novos (e inesperados) contextos de aprendizagem}

Algumas atitudes políticas e institucionais, como a adotada recentemente em alguns países (por ex.França) com a proibição total de smartphones em sala de aula, parecem ser mais uma consequência de certas percepções primárias de uso excessivo de smartphones do que uma consequência política desses estudos recentes de neurociência.

$\mathrm{Na}$ origem, desta atitude pode entender-se que o uso do smartphone cria distração e prejudica a concentração em sala de aula. Ora, estas questões estão resolvidas porque as salas de aula estão fechadas e as escolas trancadas.

Resta saber se num contexto em que a escola se evadiu do seu espaço formal, podemos atribuir ao smartphone a responsabilidade de chegar a todos os alunos, mantendo os princípios de igualdade e equidade para alunos sem computador, cuja frequência é superior nos países mais carenciados, como por exemplo, Moçambique.

\subsubsection{Diretrizes de Políticas para a Aprendizagem Móvel (2014- UNESCO)}

Este conjunto de recomendações (10) vem consagrar a utilização das tecnologias móveis como uma forma de interação entre os jovens (e menos jovens), em que se superam (mais fácilmente) diferenças, sejam elas de carácter económico, social, etc.; promovendo o diálogo como forma de gestão da aprendizagem e apresentando outros espaços possíveis para utilizá-lo, sem que se descuide do estudo (. . .)(Orrico e Monteiro, 2018:287-288).

Tendo em atenção, o atual contexto, enunciamos alguns benefícios:

- Expandir o alcance e a equidade da educação;

- Facilitar a aprendizagem individualizada;

- Permitir a aprendizagem a qualquer hora, em qualquer lugar;

- Apoiar a aprendizagem fora da sala de aula;

- Minimizar a interrupção educacional em áreas de conflito e desastre (pandemia);

- Melhorar a relação custo-eficiência.

\subsection{Smartphones e criação artística. Um campo pouco explorado em educação.}

Esse fenómeno é novo na história do homem e, como é recente, só recentemente recebeu atenção de pesquisadores (destacam-se pesquisas realizadas em Espanha: Alpuente, 2018; Assis e Farbiaz, 2018; Cassany, 2014, Cassany \& Hernández, 2012, etc.).

A multimédia utiliza vários meios (media) para comunicar (uma dada mensagem), o que torna a aprendizagem mais 
efetiva devido ao impacto da mensagem traduzido numa experiência multissensorial como nos explica Glasser e o seu conhecido esquema piramidal da aprendizagem.

É nesse contexto que pequenas telas portáteis são enquadradas, como as de smartphones que, conectados on-line, permitem que uma grande quantidade de conteúdo chegue às nossas mãos em segundos (portabilidade, econonomia, concentração de mídias).

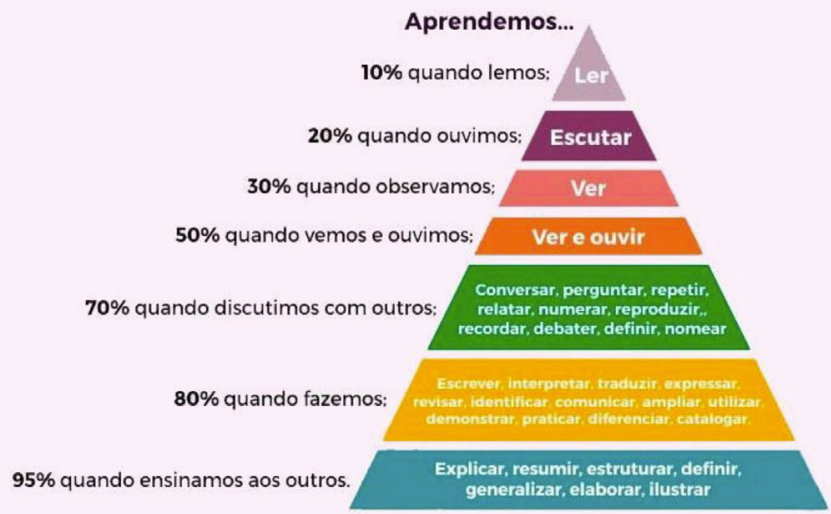

Figura 4. Pirâmide de Glasser.

Fonte: atividadespedagógicas.net

\subsubsection{Tempo e Beleza}

O retrato como tema da experimentação digital criativa.

Muitas coisas de valor não podem ser guardadas - como tempo ou beleza.(Harari, 2011:187)

$O$ retrato pode guardar as duas!

Num tempo de fluxo incessante de produção e circulação de retratos fotográficos e fílmicos, numa sociedade organizada em redor da imagem, mas que, paradoxalmente, a destrói, pelo excesso, é fundamental interrogar a vida das imagens e, em particular, qual o papel do retrato na nossa cultura. (...)

O retrato é um apelo. Olhamo-lo e somos olhados de volta.

Oferece-se e interpela-nos assim - deixemo-nos incomodar (AA VV, 2018:319).

Num tempo, cuja categoria psicológica se alterou, porque estamos sózinhos, confinados e entediados, mas sempre necessáriamente conectáveis, surge-nos a possibilidade de criar quadros de um tempo que nunca imaginamos viver, para depois (podermos) partilhar.

Estes "retratos da alma" exigem uma (re)invenção da individualidade e descoberta de subjetividade, que se evidencia na partilha.

Sou visto, logo existo (Avv, 2018:233).

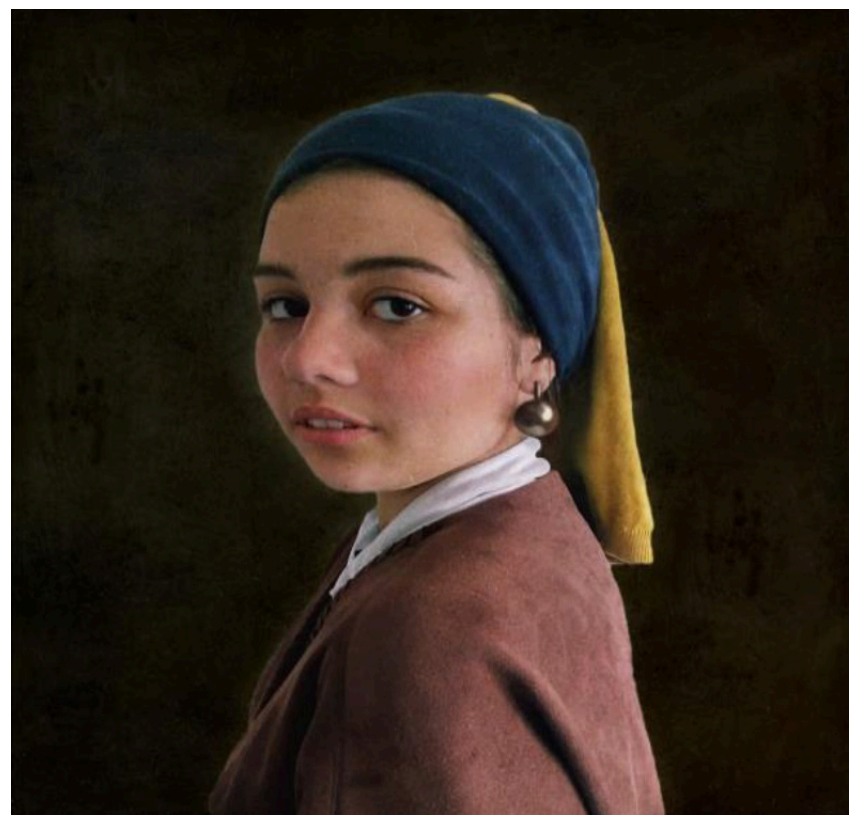

Figura 5. Trabalho escolar prático de autorrepresentação a partir da pintura de Vermeer.

Fonte: Própria (Nota: Foto publicada com autorização expressa dos alunos retratados)

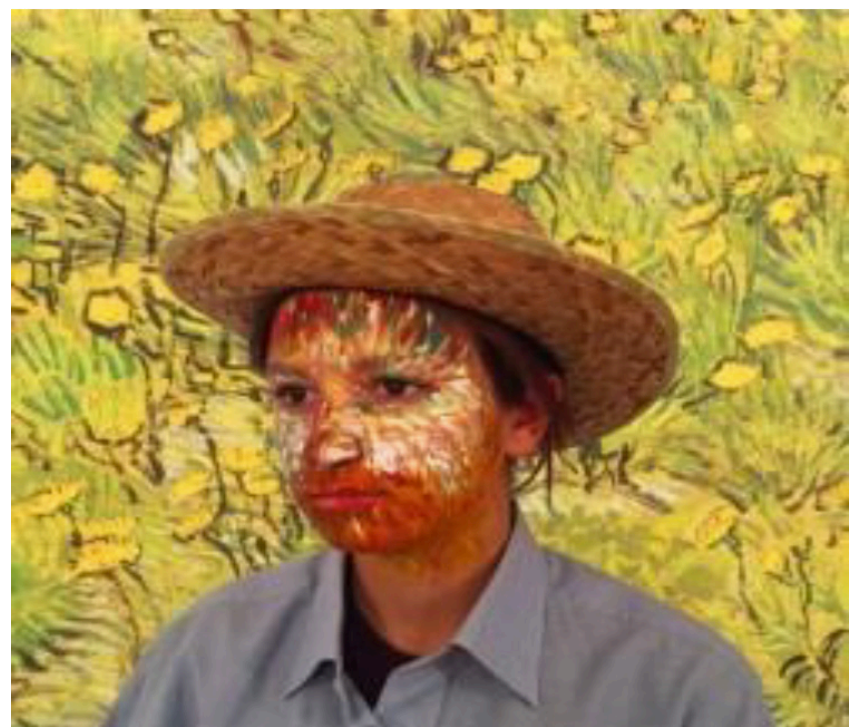

Figura 6. Trabalho escolar prático de autorrepresentação a partir da pintura deVincent Van

Gogh. Fonte: Própria (Nota: Foto publicada com autorização expressa dos alunos retratados)

Inseridos em uma cultura visual e global cada vez mais, esses alunos prosumidores são motivados pelas suas produções porque sentem o apoio emocional de uma comunidade ansiosa por vê-las. Portanto, não se trata apenas de produzir produzindo, mas de ser produzido para um público conhecido que se acredita apreciar a produção feita. 

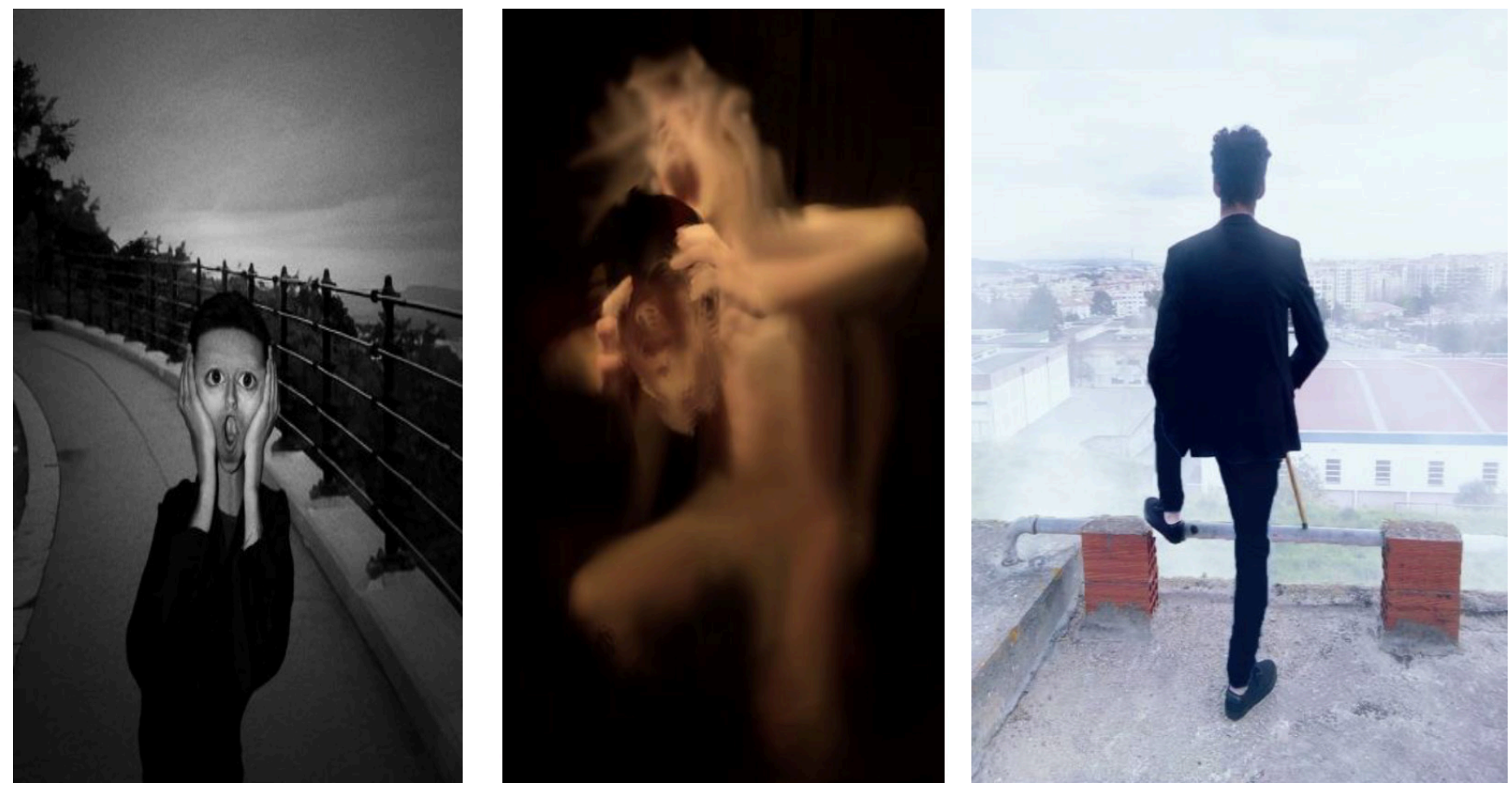

Figura 7. Interpretações de Munch, Goya e Friedrich por alunos de HCA. Fonte: Própria (Nota: Foto publicada com autorização expressa dos alunos retratados)

\section{Conclusão reflexiva}

Professores, alunos e restante comunidade, somos parte de uma enorme iconosfera formada por biliões de imagens que forma essa densa nuvem digital que está por cima das nossas cabeças.

É no que o nosso olhar nos devolve onde podemos encontrar o que verdadeiramente significam as imagens. Estamos ali, figurantes de um tempo (fisico e/ou histórico) que já não nos pertence, mas que podemos visitar nas "personagens" que lá viveram e que sobrevivem. O hoje para quem vier já será o ontem e nós estaremos no amanhã!

\section{O que fica? IMAGENS...}

Hoje, será sobretudo no (teu) dispositivo mais intímo, o smartphone. Quem quiser conhecer (a vida de) alguém basta aceder ao seu smartphone. E, é assim que se explica como a fofoca (segundo Harari, 2011) dá origem ao conceito de ideologia! Construimos estórias baseadas na História acreditanto que somos personagens vestidas de um passado para sobreviver no amanhã. No Smartphone! No Instagram...numa qualquer rede social... num qualquer canto de um qualquer país!

Cada projeto deve ser entendido como a construção de uma realidade visível, fatia de um todo que é o mundo das ideias e por conseguinte dos projetos. Por isso a Educação Artística pode sobreviver de inúmeras maneiras, usando inúmeros recursos didáticos, onde as tecnologias potenciam a comunicação e a reinvenção de uma realidade artística, lúdica e solitária que sobrevive (ou deve sobreviver) ás limitações que encontramos em locais com menos meios ou assolados por contingências especiais. O uso dos pequenos aparelhos portáteis (mais económicos que um computador) poderá minimizar diferenças de acesso a meios de registo e de de observação a qualquer hora, em qualquer lugar, permitindo a partilha e comunicação de ideias em geral, e artísticas em particular, desocultando recantos e pensamentos.

\section{REFERÊNCIAS}

AA VV (2018). Do tirar polo natural: inquérito ao retrato português. Lisboa DGPC/MNA, INCM.

Alpuente, Maria (2018). La creación audiovisual en Educación Artística. Un estudo a partir de autorretratos e Identidades desde la videocreación. Tese de doutoramento. Universidade de Valência [Consulta de 12/02/2019 disponível em URL: https://www.academia.edu/38292912/ La_creaci\%C3\%B3n_audiovisual_en_Educaci\%C3\%B3n_Art\%C3\%ADstica._ Un_estudio_a_partir_de_autorretratos_e_identidades_desde_la_ videocreaci\%C3\%B3n]

Carr, Nicolas, (2012). Os superficiais: o que a internet está a fazer aos nossos cérebros. Lisboa: Gradiva.

Case, Amber, (2014) An illustrated dictionary of cyborg anthropology. Scotts Valley: CreateSpace

Greenfield, Susan (2015). Susan Greenfield, Mind Change: How digital technologies are leaving Their mark on our brains. New York: Random House.

Harari, Yuval, (2011). Sapiens, Uma breve História da Humanidade.

[Consulta de 25/04/2020 disponível em URL:

file:///C:/Users/Jorge\%20A/Documents/Sapiens\%20Uma\%20Breve\%20 Historia\%20da\%20H\%20-\%20Yuval\%20Noah\%2OHarari.pdf.pdf

Queiroz, João, P. (2016). Educação artística e a "infirmitati ou a fraqueza analógica”. Matéria Prima, vol.4 (2), 12-17. Lisboa: CIEBA FBAUL. 